\title{
Effects of different gases on electrical properties and reliability of Ge MOS capacitors with $\mathrm{GeO}_{x} / \mathrm{GeO}_{x} \mathrm{~N}_{y}$ as gate dielectric
}

\author{
C.X. Li $i^{1, a^{*}}$, Y.Z. Zhang ${ }^{1, b}$, J.H. Zhu ${ }^{2, c}$ \\ ${ }^{1}$ Shenzhen Institution of Information Technology, Shenzhen,Guangdong, China \\ 2 Shenzhen Zhenhua Electronic Company

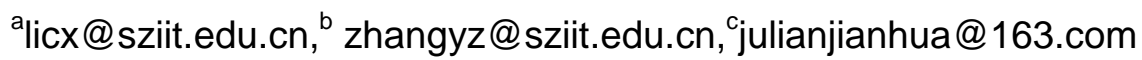

\begin{abstract}
Keywords: Germanium oxide; MOS; Reliability
Abstract. In this paper, germanium oxides/oxynitrides were prepared in different gases. The effects of different gas ambients on the electrical properties and reliability of Ge MOS capacitors were analyzed. The experiment results showed that the nitride incorporation could improve the performances of Ge MOS capacitors with reduced interface-states and gate leakage current.
\end{abstract}

\section{Introduction}

Different high-k dielectrics such as $\mathrm{HfO}_{2}$ [1-2], $\mathrm{Al}_{2} \mathrm{O}_{3}$ [3] and $\mathrm{ZrO}_{2}$ [4-5] were used as gate dielectric for Ge MOSFETs. But directly depositing high- $k$ dielectrics on Ge substrate leaded to high gate leakage current [6-7]. In order to improve the quality of the interface between dielectric and Ge substrate, $\mathrm{GeO}_{2}$ [8] and $\mathrm{GeON}$ [7] were used as an interlayer between the high- $k$ dielectric and $\mathrm{Ge}$ substrate. Both were claimed to be effective interlayers for improving device qualities. In this section, Ge MOS capacitors with $\mathrm{GeO}_{2}$ and $\mathrm{GeON}$ gate dielectrics were fabricated to compare these two dielectrics. $\mathrm{GeO}_{2}$ and $\mathrm{GeON}$ gate dielectrics were grown by thermal oxidation in dry/wet $\mathrm{O}_{2}$, dry/wet $\mathrm{NO}$ or dry/wet $\mathrm{N}_{2} \mathrm{O}$ ambient. The electrical properties and high-field reliability of these capacitors were measured. Compared with $\mathrm{GeO}_{2} / \mathrm{Ge}, \mathrm{GeON} / \mathrm{Ge}$ was found to have the better electrical properties with lower interface-state density and smaller gate leakage current.

\section{Experiment and Results}

\section{Device fabrication}

MOS capacitors with $\mathrm{GeO}_{2}$ and $\mathrm{GeON}$ gate dielectrics were fabricated on (100)-oriented n-type Ge substrate with a doping concentration of $2.65 \times 10^{16} \mathrm{~cm}^{-3}$. After cleaning and drying, Ge wafers were received thermal oxidation to grow $\mathrm{GeO}_{2}$ and $\mathrm{GeON}$. $\mathrm{GeO}_{2}$ was thermally grown at $550{ }^{\circ} \mathrm{C}$ in dry/wet $\mathrm{O}_{2}$ ambient (denoted as DO2/WO2 samples respectively) for $10 \mathrm{~min}$. GeON was prepared by dry/wet $\mathrm{NO}$ or dry/wet $\mathrm{N}_{2} \mathrm{O}$ oxidation at $550{ }^{\circ} \mathrm{C}$ for $10 \mathrm{~min}$ (denoted as DNO/WNO and DN2O/WN2O samples respectively). Then, each sample received a $500 \mathrm{ml} / \mathrm{min}$ dry $\mathrm{N}_{2}$ annealing for $5 \mathrm{~min}$ at $550{ }^{\circ} \mathrm{C}$. $\mathrm{Al}$ was thermally evaporated and patterned as the gate electrode of the MOS capacitors with an area of $7.85 \times 10^{-5} \mathrm{~cm}^{2}$. Finally, forming-gas annealing was performed at $300{ }^{0} \mathrm{C}$ for $20 \mathrm{~min}$.

\section{Results and discussions}

Fig.1 shows the typical 1-MHz HF C-V curves of the samples under dark condition, swept in both directions. It is obvious that the wet samples have larger capacitance, thus thinner gate dielectric grown in the wet ambient. A possible reason is that the growth of unstable $\mathrm{GeO}_{\mathrm{x}}$ or $\mathrm{GeON}$ with low $\mathrm{N}$ content (hydrolysable in water) is suppressed in the wet ambient, resulting in thinner gate dielectric. There are obvious bumps in the depletion regime of the dry samples, indicating interface traps in their gate dielectrics. On the other hand, the wet samples have smooth $\mathrm{C}-\mathrm{V}$ curves in the depletion regime, suggesting better quality for their gate dielectrics. 


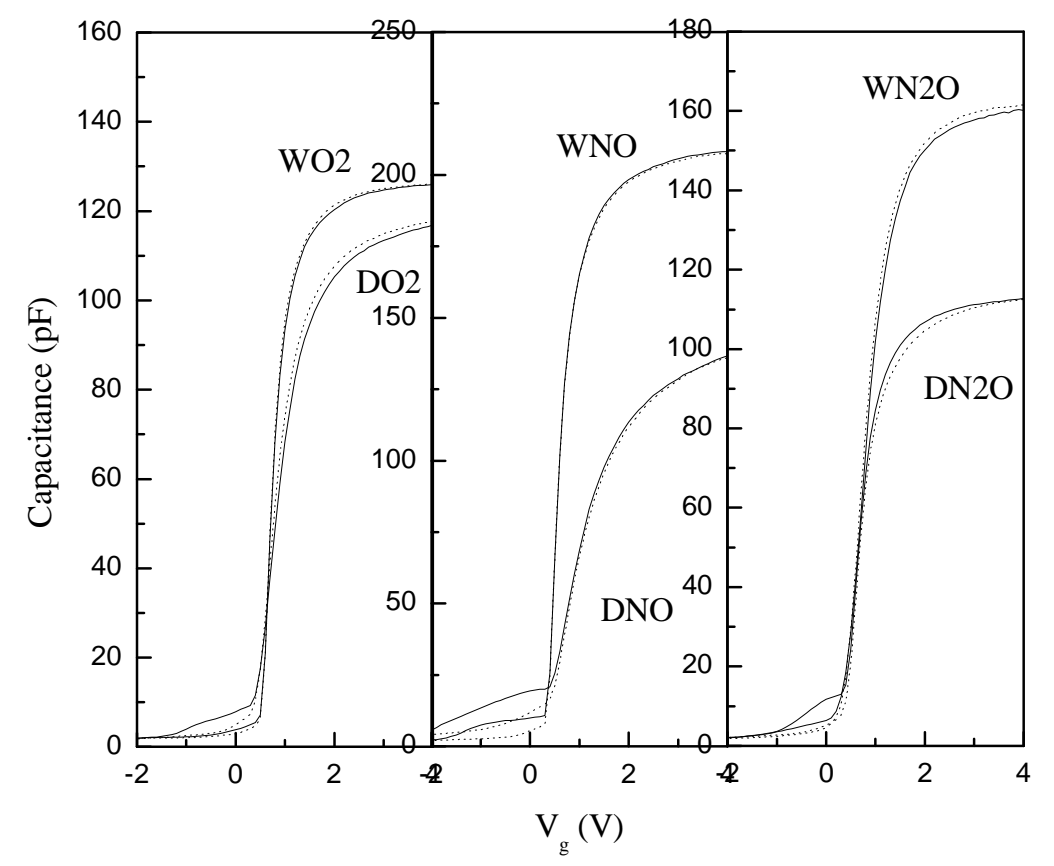

Fig.1 High-frequency C-V curves for DO2/WO2, DNO/WNO and DN2O/WN2O samples.

Table 1 Extracted parameters from high-frequency C-V curves

\begin{tabular}{|l|l|l|l|l|l|}
\hline Sample & $\begin{array}{l}C_{o x} \\
(\mathrm{pF})\end{array}$ & $\begin{array}{l}t_{e q} \\
(\mathrm{~nm})\end{array}$ & $\begin{array}{l}D_{i t} \text { at midgap } \\
\left(\mathrm{cm}^{-2} \mathrm{eV}^{-1}\right)\end{array}$ & $\begin{array}{l}V_{f b} \\
(\mathrm{~V})\end{array}$ & $\begin{array}{l}Q_{o x} \\
\left(\mathrm{~cm}^{-2}\right)\end{array}$ \\
\hline DO2 & 118.5 & 2.3 & $6.4 \times 10^{12}$ & 0.52 & $-4.25 \times 10^{12}$ \\
\hline WO2 & 126.2 & 2.1 & $2.7 \times 10^{12}$ & 0.53 & $-4.66 \times 10^{12}$ \\
\hline DN2O & 113.1 & 2.4 & $5.3 \times 10^{12}$ & 0.43 & $-3.23 \times 10^{12}$ \\
\hline WN2O & 161.2 & 1.7 & $3.1 \times 10^{12}$ & 0.52 & $-5.76 \times 10^{12}$ \\
\hline DNO & 141.4 & 1.9 & $7.3 \times 10^{12}$ & 0.46 & $-4.40 \times 10^{12}$ \\
\hline WNO & 208.7 & 1.3 & $1.3 \times 10^{12}$ & 0.32 & $-4.15 \times 10^{12}$ \\
\hline
\end{tabular}

Table 1 lists the device parameters extracted from the $1-\mathrm{MHz}$ HF C-V curves. $D_{i t}$ is determined by Terman's method for comparison purpose. In table 1 , the values of flatband voltage $\left(V_{f b}\right)$ and equivalent oxide-charge density $\left(Q_{o x}\right)$ of the WO2 sample are larger than those of the DO2 sample due to $\mathrm{OH}^{-}$-related negative charges decomposed from the wet ambient. On the other hand, the WNO sample has smaller $V_{f b}$ and $Q_{o x}$ than the DNO sample, mainly due to the $\mathrm{N}$ incorporated in the gate dielectric, resulting in positive charges and thus reduced $V_{f b}$ and $Q_{o x}$. The combined effects of $\mathrm{OH}^{-}$-related negative charges and $\mathrm{N}$-induced positive charges result in net negative charges, thus larger $V_{f b}$ and $Q_{o x}$ than those of the DN2O sample. During the wet-NO oxidation, the growth of unstable and hydrolysable $\mathrm{GeO}_{\mathrm{x}}$ and low-N-content $\mathrm{GeON}$ is suppressed, resulting in the growth of high-quality GeON with high $\mathrm{N}$ content. Among all the dry samples, the DNO sample has the largest $V_{f b}$ and $Q_{o x}$, which are attributed to the largest $\mathrm{N}$-induced positive charges in its dielectric. As compared to the Ge MOS capacitors with $\mathrm{GeO}_{2}$ dielectric, the Ge MOS capacitors with GeON dielectric have smaller $D_{i t}$, due to $\mathrm{N}$ passivating the dangling bonds at the interface between gate dielectric and Ge substrate. Among all the wet samples, the WNO sample has the smallest $D_{i t}$, due to the suppressed growth of $\mathrm{GeO}_{\mathrm{x}}$ (compared with the WO2 sample) and suitable $\mathrm{N}$ incorporation (compared with the WN2O sample) which can passivate the Ge-surface dangling bonds and thus reduce $D_{i t}$. 


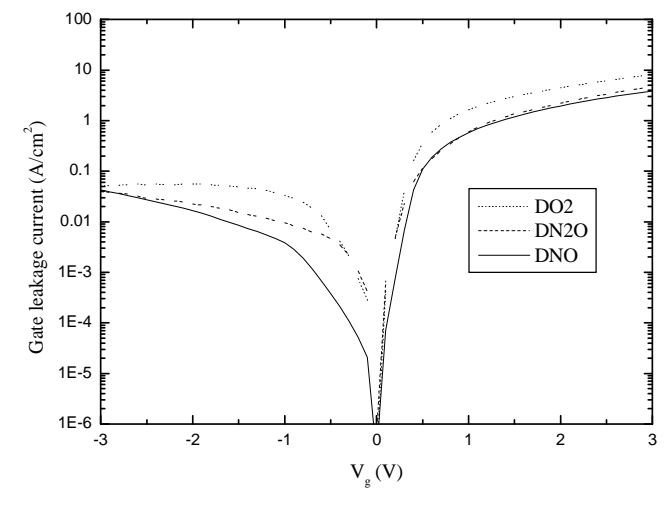

(a)

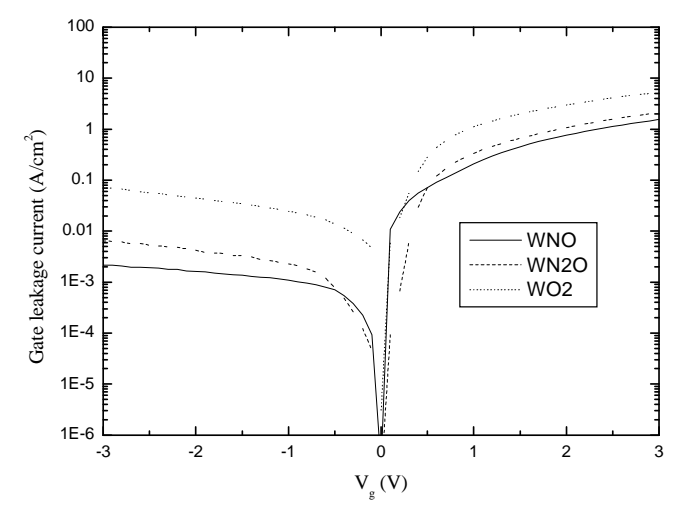

(b)

Fig.2 Gate leakage current of DO2/WO2, DNO/WNO and DN2O/WN2O samples.

Fig. 2 depicts the gate leakage properties of the samples. The dry samples show larger gate leakage current than the wet samples, due to a larger amount of unstable $\mathrm{GeO}_{\mathrm{x}}$ existing in the gate dielectric. Among all the samples, the WNO sample has the smallest leakage current, which should be due to suitable $\mathrm{N}$ incorporation, thus high quality of the gate dielectric.

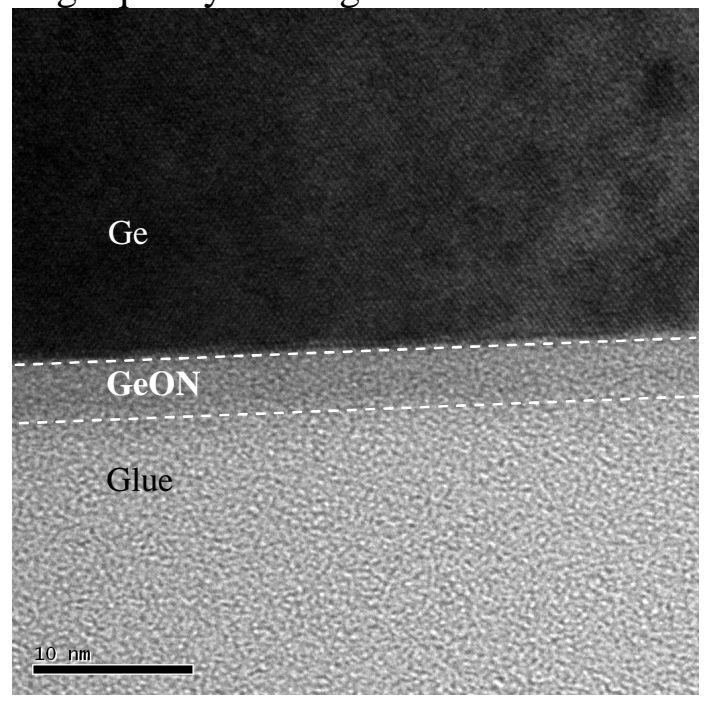

Fig. 3 TEM picture for WNO sample.

Fig. 3 shows the TEM picture of the WNO sample. It is observed that the dielectric is amorphous and has smooth interface with the Ge substrate. The thickness of the gate dielectric and the dielectric permittivity are $\sim 3 \mathrm{~nm}$ and $\sim 8$.

Fig. 4 shows the flatband-voltage shift after high-field stressing at $10 \mathrm{MV} / \mathrm{cm}$. It is obvious that the dry samples have larger flatband-voltage shift than the wet samples. This is due to the existence of a larger amount of weak Ge-O or Ge-O-N bonds, which are easy to be broken during the high-field stressing, thus generating a large amount of trapped charges. Among all the wet samples, the WNO sample has the smallest change of flatband-voltage, indicating that high-quality GeON can be grown by the wet-NO oxidation. 


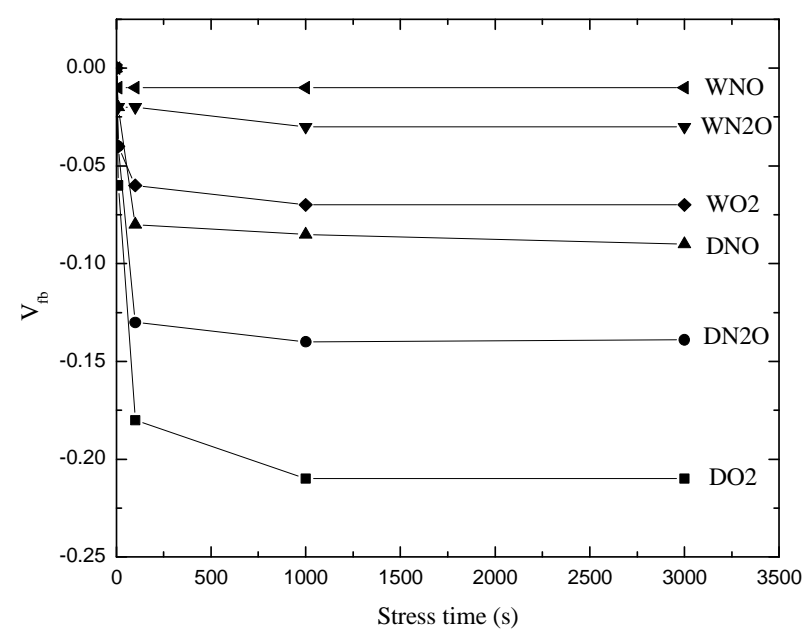

Fig.4 Change of flatband voltage under high-field stress at $10 \mathrm{MV} / \mathrm{cm}$.

\section{Summary}

Germanium oxide grown by wet/dry $\mathrm{O}_{2}$ and germanium oxynitride grown by wet/dry $\mathrm{N} 2 \mathrm{O}$ and NO were used as the gate dielectric of Ge MOS capacitors to evaluate the interface quality of $\mathrm{GeO} 2 / \mathrm{Ge}$ and $\mathrm{GeON} / \mathrm{Ge}$. Experimental results showed that the WNO sample has the lowest interface-state density, smallest flatband-voltage and smallest flatband-voltage increase after high-field stressing, indicating the high quality of the GeON/Ge interface grown by the wet-NO oxidation. In conclusion, wet-NO oxynitriditon is a promising method to prepare high-quality GeON dielectric for high-performance Ge MOSFETs.

\section{References}

[1] H. Kim, et al., "Interfacial characteristics of $\mathrm{HfO}_{2}$ grown on nitrided Ge (100) substrates by atomic-layer deposition," Applied Physics Letters, vol. 85, pp. 2902-2904, 2004

[2] C. Chi On, et al., "Atomic layer deposition of high-k; dielectric for germanium MOS applications - substrate," Electron Device Letters, IEEE, vol. 25, pp. 274-276, 2004

[3] C. James Jer-Hueih, et al., "Ultrathin $\mathrm{Al}_{2} \mathrm{O}_{3}$ and $\mathrm{HfO}_{2}$ gate dielectrics on surface-nitrided Ge," Electron Devices, IEEE Transactions on, vol. 51, pp. 1441-1447, 2004

[4] H. Kim, et al., "Local epitaxial growth of $\mathrm{ZrO}_{2}$ on Ge (100) substrates by atomic layer epitaxy," Applied Physics Letters, vol. 83, pp. 2647-2649, 2003

[5] D. Chi, et al., "Zirconia grown by ultraviolet ozone oxidation on germanium (100) substrates," Journal of Applied Physics, vol. 96, pp. 813-819, 2004

[6] S. Y. A. Ritenour, M. L. Lee, N. Lu, W. Bai, A. Pitera, E. A. Fitzgerald, D. L. Kwong, and D. A. Antoniadis, "Epitaxial strained germanium p-MOSFETs with $\mathrm{HfO}_{2}$ gate dielectric and TaN gate electrode," IEDM Tech. Dig., p. 3, 2003.

[7] S. Van Elshocht, et al., "Deposition of $\mathrm{HfO}_{2}$ on germanium and the impact of surface pretreatments," Applied Physics Letters, vol. 85, pp. 3824-3826, 2004

[8] H. Matsubara, et al., "Evidence of low interface trap density in $\mathrm{GeO}_{2} / \mathrm{Ge}$ metal-oxide-semiconductor structures fabricated by thermal oxidation," Applied Physics Letters, vol. 93, pp. 032104-3, 2008. 